\title{
Missouri's specialty crop beginning farmers cultivate resilience during COVID-19
}

Amy R. Patillo a*

University of Missouri Extension

James Curtis Millsap b

Millsap Farm

\author{
Patrick L. Byers, ${ }^{\mathrm{c}}$ Jamie A. Gundel, ${ }^{\mathrm{d}}$ \\ Katherine B. Peregoy e \\ University of Missouri Extension
}

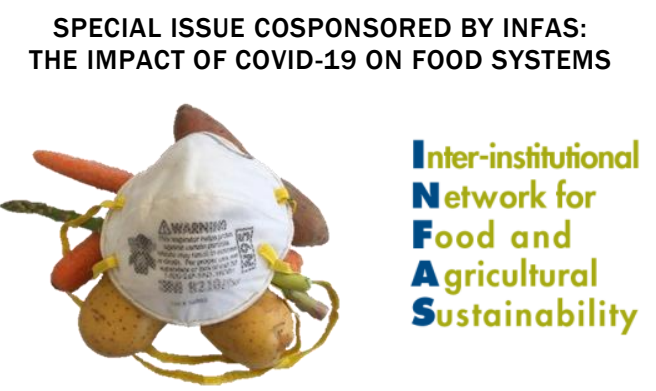

Amy K. Lake ${ }^{f}$

University of Missouri College of Education

Sarah R. Denkler, ${ }^{g}$ Eric N. Meusch, ${ }^{\text {h }}$

David L. Burton ${ }^{\mathrm{i}}$

University of Missouri Extension

Submitted October 8, 2020 / Revised December 19, 2020, and February 9 and March 22, 2021 /

Accepted March 24, 2021 / Published online April 9, 2021

Citation: Patillo, A. R., Millsap, J. C., Byers, P. L., Gundel, J. A., Peregoy, K. B., Lake, A. K., Denkler, S R., Meusch, E. N., \& Burton, D. L. (2021). Missouri's specialty crop beginning farmers cultivate resilience during COVID-19. Journal of Agriculture, Food Systems, and Community Development, 10(2), 225-239. https://doi.org/10.5304/jafscd.2021.102.052

Copyright (C 2021 by the Authors. Published by the Lyson Center for Civic Agriculture and Food Systems. Open access under CC-BY license.

a* Corresponding author: Amy R. Patillo, Associate Extension Professional, Field Specialist in Labor and Workforce Development, University of Missouri Extension; 20817 Lawrence 1170, Verona, MO 65769 USA; +1-417-331-1086; patilloa@missouri.edu

b James Curtis Millsap, Farmer Mentor, Trainer and Twilight Tour Host, Millsap Farm Owner; 6593 North Emu Lane; Springfield, MO 65803 USA; millsapfarms@gmail.com

c Patrick Byers, Extension Professional, Field Specialist in Horticulture, University of Missouri Extension; 800 South Marshall Street; Marshfield, MO 65706 USA;

byerspl@missouri.edu

d Jamie Gundel, Assistant Extension Professional, Field Specialist in Agronomy, University of Missouri Extension; P.O. Box 97; Alton, MO 65606 USA; gundeli@missouri.edu

${ }^{\mathrm{e}}$ Katherine Peregoy, Project Coordinator, University of Missouri Extension; 9135 State Highway Z; Fordland, MO 65652 USA; peregoyk@umsystem.edu

f Amy Lake, Senior Evaluator, Assessment Resource Center, University of Missouri College of Education; 204 Hill Hall; Columbia, MO 65211 USA; lakea@missouri.edu g Sarah Denkler, Extension Professional and Regional Director, University of Missouri Extension; P.O. Box 160, 147 State Hwy T; Portageville, MO 63873 USA; denklers@,missouri.edu

${ }^{\mathrm{h}}$ Eric Meusch, Extension Instructor, University of Missouri Extension; 114 West Main; Houston, MO 65483 USA; meusche@missouri.edu

${ }^{\mathrm{i}}$ David Burton, Extension Professional, County Engagement and Community Economic Development Specialist, University of Missouri Extension; 2400 South Scenic Avenue; Springfield, MO 65807 USA; burtond@missouri.edu

\section{Funding Disclosure}

This material is based on work supported by the University of Missouri Extension and U.S. Department of Agriculture, Natural Resource Conservation Service under award number 2017-0052407, USDA-NRCS-CTA-EQUIP-17-01, as well as programming supported by the Missouri Department of Agriculture. Any opinions, findings, conclusions, or recommendations expressed in this publication are those of the authors and do not necessarily reflect the view of the U.S. Department of Agriculture and the University of Missouri Extension. 


\section{Abstract}

The pandemic placed extraordinary demands on agricultural producers and created unexpected challenges for southern Missouri farmers, and pushed the University of Missouri Extension (MUE) to implement new and innovative approaches to help farmers persevere through the crisis. In surveys and reports, farmers have indicated several changes caused by the pandemic that impact their businesses, such as increase in local food demand, reduction in on-farm labor, and limitations on hosting on-farm visits with customers. The MUE StrikeForce project team, a U.S. Department of Agriculture strategic initiative, continued to serve farmers by developing alternative educational opportunities that incorporated social distancing and other preventative actions, and were of immediate use to farmers in a crisis. Several of the educational approaches, including video conferencing, online teaching, digital recordings, video repositories, social media communications, pick up and drop off locations, and the use of multiple online viewing platforms such as Zoom recordings have proven to be effective in helping farmers sustain their businesses and have substantially increased access to programming across the state. The convenience of accessing education and learning opportunities online also appealed to more participants. Overall, online educational delivery was positively received by producers, demonstrating the efficacy of digital learning when paired with offline resources and support from the StrikeForce project team. After the pandemic ends, MUE will continue to implement these approaches. Nevertheless, the traditional Extension approach of one-on-one consulting and farm visits cannot be completely replaced by online educational programming. The pandemic has highlighted inequities faced by many rural Missouri farmers that lack dependable internet or cell phone network access, and had no access to StrikeForce programming when face-to-face visits were paused.

\section{Keywords}

COVID-19, Coronavirus, Disruption, Extension, Food System, Online Training, Pandemic, Small Farmer, Beginning Farmer, Specialty Crop, StrikeForce

\section{Introduction}

When COVID-19 first reached Missouri in March 2020, University of Missouri Extension (MUE) faculty were active in the field through the StrikeForce project, providing workshops to small farmers in southern Missouri. In response, Cooperative Extension specialists were forced to adapt their training and educational resources that were targeted to beginning farmers. This study describes the StrikeForce initiative and its relationship with MUE, presents the changes made to educational programming due to the COVID-19 pandemic, and reflects on MUE's response to the pandemic and its path forward.

\section{Extension Programming to Address Audience Diversity}

"We were in the right place, at the right time," reports the StrikeForce project team. (J. Gundel, personal communication, September 24, 2020)

The U.S. Department of Agriculture StrikeForce Initiative for Rural Growth and Opportunity is a strategic initiative that provides funding to 46 rural counties in Missouri to address their persistent poverty (U.S. Department of Agriculture, 2016b). According to the USDA, $85 \%$ of U.S. counties with severe chronic poverty are rural; more than one-third of rural adults and one-quarter of rural children live in poverty (U.S. Department of Agriculture, 2016a). The StrikeForce initiative addresses specific challenges associated with rural poverty by investing in rural communities to increase opportunities for families. The initiative delivers targeted assistance to grow the economy, create jobs, build healthy homes, feed children, assist farmers, and focus on natural resource conservation, with the overall goal of reducing rural poverty.

The StrikeForce initiative demonstrates the USDA's commitment to the economic future of America and directly aligns with the MUE mission, to "improve lives, communities and economies by producing relevant, reliable and responsive educational strategies that enhance access to the resources and research of the University of Missouri" 
(University of Missouri Extension, 2021). The Missouri StrikeForce Farmer Development project was established by MUE, based on the USDA directive, to provide education and training in commercial specialty crop production with a focus on increasing partnerships in rural communities and leveraging community resources in targeted areas (U.S. Department of Agriculture, 2016a, 2016b). Through this project, MUE has engaged with more than 1,500 farmers throughout StrikeForce designated counties since 2017, to provide them with educational opportunities and enhance their businesses. The USDA StrikeForce initiative identifies 46 rural counties in southern Missouri that demonstrate indicators of chronic poverty and have the potential for economic development (Figure 1).

For the last three years, the StrikeForce project has targeted areas of Missouri that need an economic boost and can benefit from the expansion of small farms and on-farm businesses. The programming provided is tailored towards beginning farmers who are interested in specialty crop pro-

Figure 1. Forty-Six StrikeForce Counties in Southern Missouri

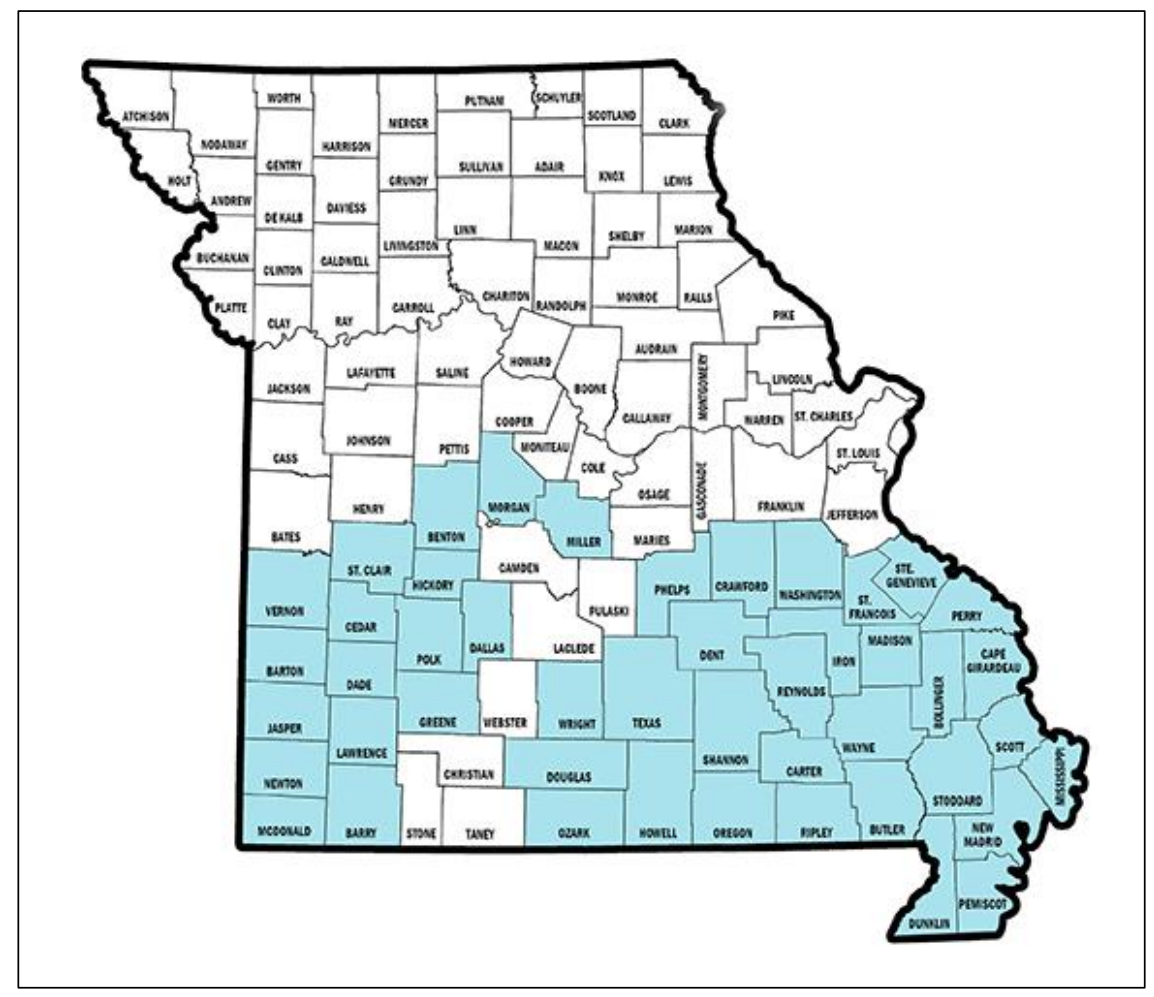

Source: U.S. Department of Agriculture, Natural Resources Conservation Service Missouri (n.d.). duction, want to increase their knowledge of farming and business, and would benefit from ongoing support provided through peer-to-peer and mentor-to-mentee relationships. Many project participants are interested in home gardening, would like to grow specialty crops, and do not identify as farmers. The project has expanded educational opportunities to farmers in StrikeForce counties to assist them in improving the efficiency and profitability of their operations while emphasizing the conservation of natural resources. The financial assistance received from the Natural Resource Conservation Service has allowed the project to increase educational offerings, including in-the-field consultations and workshops on conservation practices associated with specialty crops.

The horticulture programming provided through the StrikeForce project coordinates educational resources and opportunities among many disciplines, including agronomy, agriculture education, agriculture business, community development, 4-H youth programs, and labor and work-

force development. Prior to the StrikeForce project, educational opportunities were only provided to producers by MUE through workshops in a lecture setting. MUE had not yet incorporated peer and mentor farmers to host farm tours or educational programs into their educational offerings. As a result, MUE had difficulty connecting specialty crop growers to longterm educational programs, especially in south central and southeastern Missouri.

Through the StrikeForce project, Extension specialists with MUE developed, implemented, and assessed agricultural and specialty crop programs with a focus on longterm impacts. The specialists created new relationships with farmers by touring their farms and providing them 
with on-farm educational programs and resources to market and promote StrikeForce workshops. The development of new relationships between the specialists and specialty crop producers paved the way for on-farm programming with established farms producing specialty crops. These new relationships between producers and Extension specialists, as well as the longer-term relationships developed before the project, were crucial in allowing MUE to easily pivot and quickly respond with different approaches to StrikeForce programming as the agricultural implications of the COVID-19 pandemic became clear.

In response to the ongoing needs of producers and the safety concerns of the pandemic, programming transitioned to online. Workshops, consultations, farm tours, and other planned events were delivered online instead, with marketing and promotion extended to a statewide audience (Lake et al., 2020). However, audience diversity, heightened by the nature of Missouri's agricultural products, created challenges for online teaching and delivery methods. The producers in the targeted counties are diverse in their scale of operations, types of crops, growing techniques, and marketing approaches; they also come from diverse cultural and ethnic backgrounds.

The USDA defines a small farm as an operation with a gross cash farm income under $\$ 250,000$ (USDA, 2017). Missouri has more small farms than any other state and is unique in its number of agricultural focuses of production. Where most states have one or two primary agricultural focuses, Missouri has many, including cattle and calves, hogs, broilers, turkeys, dairy products, hay, rice, chicken eggs, commodity crops such as soybeans, cotton, corn, and grain sorghum for livestock feed, and horticulture specialty crops (USDA, 2017). Specialty crops offer producers an opportunity to receive reasonable incomes from small-scale farming operations. Specialty crop production works especially well for farmers challenged by Missouri's landscapes and land requirements, as it gives them a competitive advantage with less investment in land.

The COVID-19 pandemic affected all industry and agriculture sectors, accelerating changes in market demand and impeding sales while creating a global health crisis with devastating economic impacts. Although agricultural producers' ability to get product to consumers was affected by community-wide measures implemented to contain the spread of COVID-19, many farmers maintained viable on-farm production and continued sales. The StrikeForce team's ability to respond to producers' challenges was critical during the pandemic, especially with the diversity among farm activities. StrikeForce supported producers' efforts to diversify with specialty crops and to adjust their scale of operations based on pandemic conditions. The project team's rapid response, readiness, and troubleshooting abilities through a pandemic were not planned. When asked about their efforts, the team reported that they never considered anything else: "It is just the way we do it." (P. Byers, personal communication, September 24, 2020).

\section{Limitations to Programming Access}

The StrikeForce counties in southern Missouri also represent the counties with the state's lowest levels of broadband access (Missouri Broadband Resource Rail, 2019). In addition to those with limited broadband access, StrikeForce audiences include individuals without broadband internet and people that do not use digital formats at all, such as the Amish population.

Access to StrikeForce programming for diverse farmer audiences is important. In an analogous situation, Washington State University researchers piloted various alternative educational formats (e.g., participatory courses, farmer-tofarmer learning strategies, experiential workshops, audiovisual strategies, and simultaneous translation) for reaching diverse producers to address the challenges they face when accessing public agricultural research, education, and assistance (Ostrom, Cha, \& Flores, 2010). Strikeforce addressed similar barriers for audiences both during and after the pandemic, which hamper the ability of MUE to provide educational programming when also following guidelines preventing face-to-face interaction. In the absence of face-to-face trainings, StrikeForce team members made accommodations necessary to serve local farmers. For example, in lieu of providing in-person pesticide applicator training, the team delivered training manuals to lo- 
cal produce auctions. While maintaining distance and following precautions, team members handed out manuals and training questionnaires and picked them up the following week. Other accommodations included mailing information, addressing onfarm issues through emailed and texted photos, and video conferencing and phoning to work with farmers. The Amish clientele in Webster County, Missouri, who do not own cell phones, asked NonAmish acquaintances and neighbors who do own cell phones to take pictures and forward them to Extension specialists to address plant diseases, changes in plant appearance, and general questions about plant culture. In these cases, it was essential that specialists responded quickly because the individual with the phone would only be available for

\section{Figure 2. Missouri Broadband Access Map}

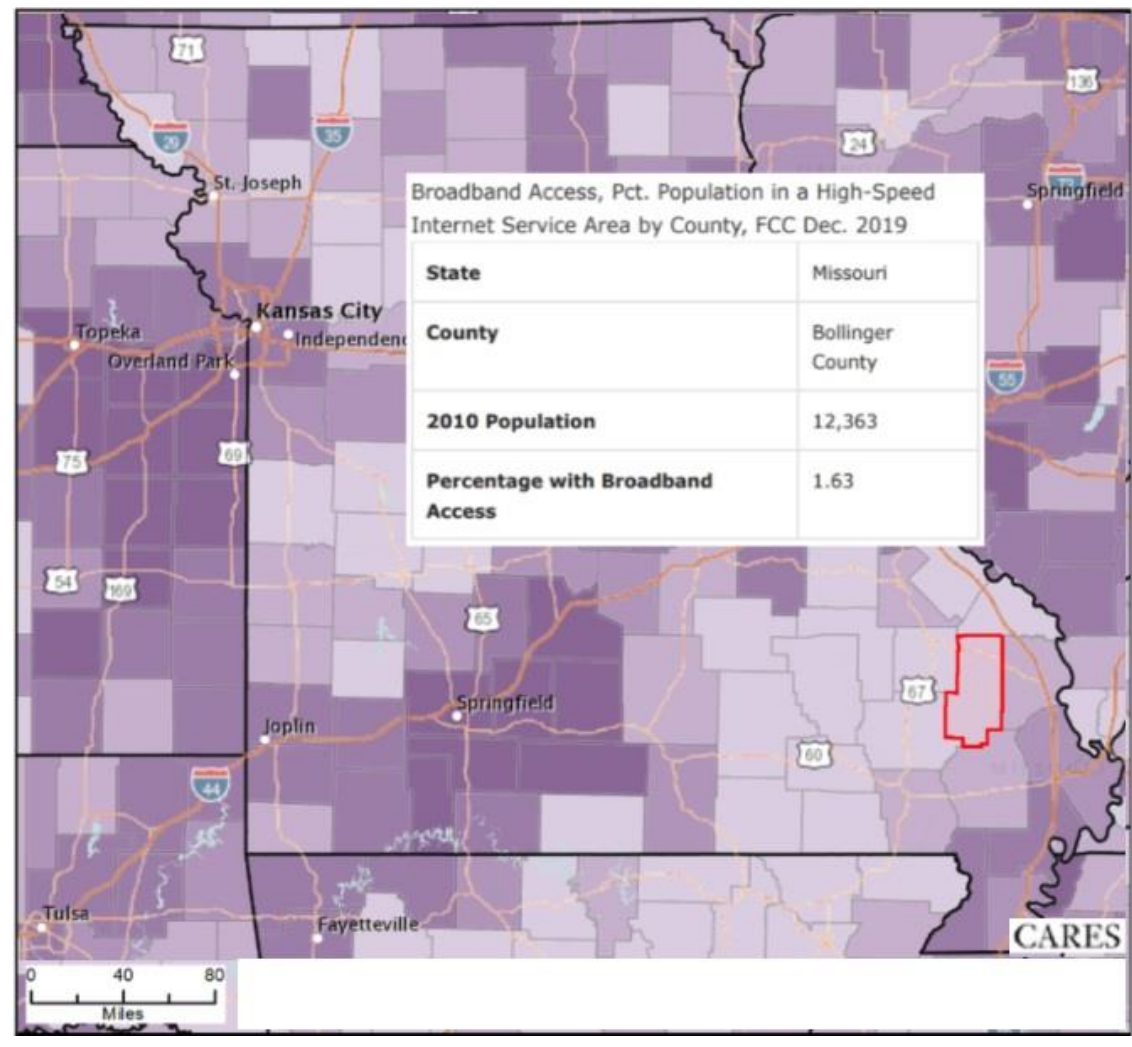

Broadband Access, Pct. Population in a High-Speed Internet Service Area by County, FCC Dec. 2019

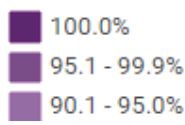

$70.1-90.0 \%$

$0.01 \%-70.0$ No Coverage or No Data about 10 minutes before leaving the Amish farm. While this may not have been the most effective method, it overcame a challenge posed by the pandemic and addressed the ongoing programming needs of Amish farmers.

The pandemic has highlighted the imperative need to expand broadband access in preparation for future responses and movement into online education. However, the pandemic also reinforced the importance of expanding and maintaining farmer networks that can help introduce new research and technology concepts to audiences that are very difficult to reach due to limited digital and broadband access (Figure 2).

As Missouri improves broadband, as a picture of uneven development has emerged, it is important to note that the reality seems to be far worse than the data suggests. For example, according to the American Community Survey, while $61 \%$ of the population in Bollinger County, Missouri, cannot connect to any internet service whatsoever, only $1.63 \%$ can get broadband ( 25 megabits per second [MBps] and upload speeds of at least 3 MBps) (Missouri Broadband Resource Rail, 2019). These broadband speeds are identified by the Federal Communications Commission (FCC) as sufficient to allow people to work remotely, stream movies, and use telehealth but are below the recommended requirements for Netflix, gaming systems, and other streaming devices that require from 5MBps to $75 \mathrm{MB}$ ps (Federal Communications Commission, 2016). Microsoft data is fairly consistent with the FCC data, reporting that only 2.1\% of people in Bollinger County use internet at broadband speeds (Missouri Broadband 
Resource Rail, 2019). As the broadband issue is addressed in Missouri, more data must be gathered to determine a true representation of Missouri residents' access to adequate broadband speeds (University of Missouri Center for Applied Research and Engagement Systems, 2019).

\section{COVID-19 Survey of Southern Missouri Farmers}

To explore the immediate impacts of the pandemic on small farmers in specialty crop production, the StrikeForce team implemented a short, focused survey among the participants in StrikeForce-sponsored workshops. The survey targeted small specialty farmers in the 46 designated StrikeForce Counties in Missouri to understand quality improvement measures and the impact of the pandemic on farmers. The team had established relationships with specialty crop producers before the pandemic. In March 2020, in response to the pandemic, the StrikeForce project began adapting their program delivery models and creating new opportunities to support farmers as their needs evolved. In June, farmer feedback indicated that many direct-to-consumer sales and farmers market venues had transitioned to alternative approaches. At this time, StrikeForce determined it was important to survey producers in order to assess their programming and outreach efforts as modifications and adaptions continued.

\section{Survey Methods}

The MUE StrikeForce project team, in partnership with the University of Missouri Assessment Resource Center, conducted a web-based survey through Qualtrics in June and July 2020. (The Missouri StrikeForce Farmer Development Quality Improvement Project does not require IRB review, as determined by the University of Missouri IRB Determination Notice for Project \#2043562 Review \#294172.) The purpose of the survey was threefold. The first purpose was to determine the ongoing needs of farmers following their participation in StrikeForce programming. Second, the survey gathered basic information about the immediate effects of the pandemic on participant agricultural operations since programming had moved to online delivery in March 2020. The third purpose was to assess project outcomes and measure the progress of quality improvement and program development initiatives offered through the StrikeForce project. The survey acquired farmer feedback on the specific educational programs provided by the StrikeForce project. It provided the project team with recommendations to improve the services provided by Extension specialists, assessed the need for program delivery methods, and provided information on how farmers had implemented the resources and training tools furnished in the project. StrikeForce programming attracted a wide audience, including those who are not residents of StrikeForce counties and those who have indicated an interest in farming but were not yet established farmers.

The survey consisted of 24 questions, including eight demographic questions and 16 multiple choice, yes/no, and open-ended questions regarding farmer status, crops and products, responses to the pandemic impacts, and participation in online programming. Text entry boxes were included on all multiple-choice questions to allow for comments, resulting in many direct quotes from farmers. This strategy was important, as the StrikeForce specialists did not want to make assumptions about how the pandemic was affecting farmers. Survey questions pertained to farming practices, the direct agricultural impacts of COVID-19 including pandemic control plans, changes in product demand, modifications to farm operations, farm worker assistance, perceptions of the food system, farmer needs, and basic demographics. Survey questions were not translated into Spanish or other language due to time and resource constraints. Although preliminary due to the small number of responses, the survey data may be helpful for designing future studies, surveys, and programming.

Of the 1,500 StrikeForce workshop attendees (2017-2020), 301 met the criteria for the targeted sample and were invited to respond to the survey. The targeted sample for the survey were those who self-identified as farmers or growers, resided in a StrikeForce Missouri county, had attended at least one StrikeForce workshop, and had a current email address. Surveys were sent via email with a personalized message from a StrikeForce team member in two waves, in June and July 2020. Twenty-two of 
the 46 Missouri StrikeForce counties were represented in the survey. Twenty-two percent of survey respondents resided in Greene County, where Springfield, the major metropolitan hub for south central Missouri, is located. Incentives were not provided for participation in the survey. The response rate was $15 \%$ (44 responses out of 301 surveys sent). Numbers of respondents (n) varies by question because some respondents did not answer every question in the survey. The survey sample was limited by the procedure of delivering questionnaires to assess the impact of COVID-19; employing additional survey tactics to increase response rates, such as incentives, a pre-selected survey research panel of participants, or text message prompts and reminders could have resulted in increased responses. Specific to the Amish participants, in-person interviews or focus groups are good options for collecting survey information.

\section{Survey Results}

\section{Demographics and Key Characteristics}

The survey demographics reflect the specific audiences targeted by the project, including beginning specialty crop growers and home gardeners, which are an appropriate pool of candidates for the StrikeForce area. Individuals were only targeted for the survey if they self-identified in general as beginning farmers. However, the survey asked the grower to specify which type of beginning farmer they were: home gardener, commercial grower, or both. A producer often is more than a home gardener and does not realize it, perhaps due to the limited land required for growing specialty crops. These farmers may not classify production as commercial sales or define the level at which they are producing as commercial. The majority of survey respondents self-identified as home gardeners or both home and commercial growers (93\%). Only seven percent identified solely as commercial growers.

One-third (36\%) of respondents were employed full-time, and $40 \%$ were retired. One-third $(35 \%)$ were 65 or older, one-third $(33 \%)$ were between 54 and 65, and one-third (30\%) were between 35 and 54 . Respondents were $56 \%$ female and $44 \%$ male. Most respondents self-identified as white $(86 \%)$ and $14 \%$ identified as one of several non-white races (Black or African American; Asian; Native Hawaiian or Other Pacific Islander; Native American or Alaska Native). Ten percent identified as veterans, and less than $3 \%$ identified as having a disability. The agricultural enterprises represented by survey respondents included U-Pick, diversified fruits and vegetables, poultry (chicken and turkey) meat birds and layers, farm raised pork and beef, sales production for farmers market and drop-off deliveries, sales for customer pick up, small direct marketing operations, and online sales.

\section{Effects of COVID-19}

To the question "Has COVID-19 affected your plans to launch your commercial agricultural venture?", $56 \%$ of respondents $(n=16)$ said "yes." Respondents were asked to describe the effects in an open-ended question. Specific details of effects varied greatly, but showed general agreement among respondents for delaying business expansion. Examples of the effects reported include delay in raising broilers (meat chickens) because purchase price was four times the usual cost, low prices for weaned calves, holding off from joining farmers markets due to contact restrictions, a halt in raising steers because of a two-year backlog at local meat processors.

Three-quarters ( $73 \%, n=22$ respondents) of respondents said that they are implementing a pandemic control plan on their farms. Farmers reported that they are increasing the safety precautions on their farms by limiting the number of customers/visitors, changing the ways in which they transfer products to customers, reducing or eliminating on-farm workers, implementing physical distancing measures for farmers market workers, and wearing face coverings. In some cases, farmers reported that their family members were working longer hours due to the restrictions that eliminate workers, visitors, and on-farm sales, and relying on customers to pick up purchases at drop points or farmers markets. Respondents implementing pandemic control plans said the following, regarding changes they have made:

- Minimal contact. U-Pick in buckets (customers) keep and leave versus (selling) by 
the pound which (requires) handling. Set private smaller group picking dates for those sensitive to crowds, social distancing, masks and cleaning when required."

- "We bring out the order to the customers' cars, so they do not have to get out. We wear masks if someone happens to exit their car."

From March 2020 to June/July 2020, 52\% $(n=21)$ of respondents reported that the demand for their products had increased since the outbreak. For example, one respondent said: "I have taken the unprecedented step of purchasing livestock for processing in order to try and meet demand. My red meat processor is completely booked through 2021." One-fifth (19\%) reported no change in demand, and 14\% reported a decrease in demand. (The remaining 15\% selected "other" and did not provide a comment.)

Three survey respondents (14\%) reported that they or their farm workers had applied for COVID-19 Emergency Relief Funds ( $n=22)$. Relief Funds were not conducive to small farmers due to the required parameters for documenting contracts and sales through formal marketing channels. Farmers market records may not provide the necessary documentation for farmers to apply for Relief Funds.

Eighty-two percent $(n=33)$ said that the COVID-19 pandemic had affected the way they view the food system (where and how they buy food, where it comes from, etc.). There were 24 unique answers to this open-ended question. Most respondents said that they had an increased appreciation of the importance of local food, a clearer understanding of the vulnerability of a centralized food system, increased concerns about the cost and availability of food, and increased concerns about sanitation practices for food suppliers. Some illustrative quotes:

- "Very concerned as to where food originated and how it was handled from start to finish of cycle."

- "We've tried to buy as much as possible from our local small-town grocery store ... Put in irrigation system to try to get more yield from our home garden."

- "Yes, buying local is more important. We should have less dependence on goods that need to travel long distances."

- "Yes! Did much more canning this year than usual."

- "COVID-19 has made my household want to start raising and growing more of our food in order to have a consistent, safe food supply."

Less than half of the respondents (44\%) said that they had participated in web-based trainings, workshops, and discussions related to farming or gardening since the pandemic began $(n=43$ respondents). Since the survey itself was web-based, there is selection bias in this question. When asked about internet connectivity ( $n=19$ respondents), $74 \%$ said that their internet connectivity had been sufficient for full participation in web-based events "most of the time," which was defined as at least $90 \%$ of the time. One-fifth $(21 \%)$ said it was sufficient "sometimes" (over 50\% of the time) and only $5 \%$ said it was sufficient "occasionally" (less than $50 \%$ of the time). Of those who said that they did not participate in web-based trainings $(n=24), 38 \%$ said that they did not need or want the training, $21 \%$ said that they were not familiar with video conferencing technology (e.g., Zoom), and 29\% had "other" reasons.

\section{Discussion of results}

The survey sample is representative of the whole StrikeForce participant population of 1,500 in terms of age, gender, employment status, race, and diversity of agricultural activities. The survey sample does not seem to include the significant Latinx, Amish, Mennonite, and Southeast Asian (primarily Hmong) populations served by StrikeForce, nor does it include the prison population served (Byers et al., 2020). The survey does have selection bias because it was completed only by StrikeForce participants who had active email addresses, had access to the internet, and were English-language speakers/readers.

Nonetheless, some important observations can be made. The pandemic has resulted in increased demand for local food and the services of local 
grocers and food processors such as meat processors, according to this survey. At the same time, local growers, as represented in this survey, have been pinched in their capacities to produce more food products for several reasons, including higher prices of inputs and supplies, overdemand at local meat processors, restricted access to customers onfarm, and increased labor by farmers and farmer families due to restrictions among farm laborers.

\section{COVID-19 Impact on Educating Small Specialty Crop Producers}

Extension specialists were quick to observe the changes made in participant agricultural operations, based on their initial reactions to the pandemic beginning in March 2020. There was consensus among the team that a better understanding of these changes should be sought, prompting a survey of the effects of the pandemic which was conducted in June and July 2020.

Once social distancing was implemented to restrict the spread of COVID-19, specialists had to become creative with their educational programming: developing videos in place of live demonstrations, providing classes online either through Facebook Live or Zoom, providing materials ahead of time through email or in-car pick up, answering questions during livestreams, sending and receiving pictures on cell phones or observing with video via cell phones. The StrikeForce team had to remain mindful of how to serve those without broadband or any internet access.

\section{COVID-19 Programming Pivot}

The StrikeForce team pivoted programming in response to the COVID-19 pandemic disruptions to continue providing programs and ongoing support for producers. In addition to delivering virtual workshops, the StrikeForce farmer mentor model became a critical tool for farmers to check in with one another, have a resource for answering questions, and obtain support when experiencing distress or crisis. Programming pivots created opportunities to try new educational delivery systems, create sustainable tools with online access, and utilize mentor and peer networks that are essential to StrikeForce programs.

\section{Prison Training}

Before the pandemic, the StrikeForce project, in collaboration with One-Cert Organics, offered four training sessions for inmates at the Southeast Correctional Center in Charleston, Missouri. These training sessions focused on produce food safety and blackberry production. The sessions helped 51 inmates scheduled for release gain marketable skills, with 21 of these inmates receiving certification for attending produce safety training for the Food Safety Modernization Act (FSMA) offered through the Produce Safety Alliance (PSA). Due to restrictions put in place by the prison in response to the pandemic, in-person courses were halted. The produce safety training curriculum was quickly modified to a shorter overview which was delivered remotely to the prison. The FSMA PSA produce food safety training consists of a mandated 8hour curriculum that is delivered in person, remotely (with real-time video connection to each trainee) or virtually (each attendee must have an internet connection that allows for asynchronous training). None of these three delivery options were viable given COVID-19 restrictions (and prison-related restrictions in general), so the team quickly pivoted to create a modified training that was of shorter duration and delivered remotely without individual video connections with the trainees as approved by the prison. The modified training delivered an overview of produce food safety in a 2-hour presentation, based on the modules of the FSMA PSA training. The team hopes to revisit the trainees (both those in the prison and those who have left prison) at a later date with an opportunity to take the full FSMA PSA training.. Inmates were also invited to reach out to the training team upon release to participate in the full produce safety training.

\section{Apple Grafting Workshops}

With apple grafting workshops scheduled to begin only a few days after COVID-19 restrictions were put in place, the workshops had to be adapted for a virtual platform with very short notice. Traditional grafting workshops included classroom instruction, in-class demonstration of grafting techniques, and hands-on experiential learning by attendees. Given the COVID-19 restrictions, the StrikeForce team 
developed a series of internet-posted videos describing all aspects of apple grafting, prepared and distributed packets of grafting supplies to all attendees using a drive-through pickup system, and conducted a virtual workshop that utilized these resources. The team offered monthly follow-up support for workshop attendees. Reported knowledge among participants ( $n=18$ respondents) of workshop topics before and after the training, on a 1-4 scale, increased by at least 1.42 points (sample mean); average knowledge level improved from 2.1 to 3.5 .

The unanticipated change in venue resulted in valuable and unintended consequences. First, the workshop recordings and grafting videos are now ongoing training tools for workshop attendees and others. Second, the video training for this topic reduced participant concerns for exposure and illness. Third, the adapted process allowed specialists to build trusting relationships and maintain connectivity with growers, which has been especially important during the pandemic. In the virtual format, however, it was impossible to observe and critique grafting technique or to support self-collection of scion wood. But specialists still followed up with participants, who were very appreciative of the additional assistance. Fourth, the videos were well received, and are better suited to demonstrate some techniques that are difficult to demonstrate in a classroom setting (i.e., cleft grafting, T-budding). The StrikeForce team will continue to use these videos once in-person workshops are safe to resume. Despite the success of the impromptu virtual training sessions and videos, workshop attendees reported an interest in returning to in-person trainings.

\section{Twilight Tours}

Prior to the pandemic, the StrikeForce project partnered with Millsap Farm owner Curtis Millsap for a monthly twilight tour on his farm that included a walk-around tour and an in-depth discussion of specialty crop production. The tour consisted of 11 in-person sessions and included up to 40 attendees per session. In response to the COVID-19 restrictions, Millsap and his farm team prepared video and still photos as well as offering virtual tours online. The virtual tours were recorded and posted as an ongoing StrikeForce resource. As COVID-19 restrictions were eased later in the summer, in-person tours resumed in accordance with the COVID-19 recommendations to limit the number of attendees, wear masks, and socially distance, as well as other precautions to ensure the safety of on-farm participants.

Twilight tours were a highlight of the StrikeForce project before the pandemic, and the team was unsure how participants would react to the format change. Surprisingly, the team found that it is possible to alter an inherently face-to-face experience when there are existing relationships in place with participants. Many twilight tour participants already knew Millsap and had been involved in other StrikeForce project events. Based on the established trust, strong relationships, and concern about the pandemic, participants were willing to adjust to the new format. Serving as a mentor to growers, Millsap stated: "COVID-19 accelerated change for people to jump in and have a market for people that are hungry for their product. No one should be daunted; in fact, people should be encouraged to take that lead. They can make this part of their transition plan as they explore how to leave that paycheck behind and jump into farming full-time. It is a unique opportunity for people to have the little boost they need to get started." Reflecting further on calls received from farmers during COVID-19, Millsap said: "I received more calls from farmers wanting to check-in, to make sure that they are okay, I am okay, and that we were all experiencing the same (issues) in the face of events brought on by the pandemic. During COVID-19, growers demonstrated they are nimble, responsive, and able to deal with adversity, because there are not the support systems in place in absence of broadband. You form a network of peers and someone has the information you can benefit from." (personal communication, September 25, 2020).

Ozark Ag 101

The Ozark Ag 101 program had been proposed by the StrikeForce team before the pandemic but had not yet been implemented. Ozark Ag 101 was intended to provide introductory information to beginning farmers in the Ozarks, including farmers 
new to farming, new to farming in the Ozarks, or interested in a new enterprise on an existing farm. The team identified the target audience for Ozark Ag 101-beginning farmers, many of whom would be younger and familiar with online technologiesas another suitable demographic to reach with an online format when the pandemic reached Missouri. The program was held via Zoom, consisting of eight online sessions over a four-week period. As with the apple grafting workshops, the online technology allowed delivering the content remotely as well as recording the sessions for later viewing. Of the 29 participants, 16 were from 11 Strikeforce counties. The remainder were from other counties in the state or out of state. Eighty-six percent of those that responded to a course evaluation survey enjoyed the online format, $14 \%$ enjoyed the format but would have preferred face-to-face, and none claimed to dislike the format. Fifty-seven percent of survey respondents only participated in the live Zoom events, and $43 \%$ participated in the live events and watched recorded sessions. Some quotes provided in the immediate impact surveys from participants:

- "I really enjoyed this program. It was a refresher on some topics, but I gained some much-needed knowledge of sites I can use to fine tune my marketing plans for berry production and possibly a market garden venture with my adult children. I have more time available than they do to take these courses and become a help to them."

- "I think Zoom allowed participants from all over the state to join, instead of waiting for the local team to schedule a class."

\section{Individual Consultations during COVID-19}

Individual consultations with growers have been an important educational tool used by specialists since the beginning of the StrikeForce project, providing farmers with technical advice based on their specific needs and situations. Extension specialists typically conduct these consultations in person so that they can better grasp the issues and determine which concerns on the farm need to be addressed. The COVID-19 restrictions prevented in-person meetings and forced the team to develop alterna- tive approaches to offer this service. Information on how to access resources and contact Extension specialists was made available to the public through online and local newspaper announcements while the local Extension Centers were closed. Drop boxes for soil samples were established in some Extension Centers to avoid face-to-face interaction and follow-up was completed by telephone or email. In many cases, producers were able to send pictures and videos to specialists for evaluation and recommendations. Of course, these virtual farm consultation techniques were unavailable for producers without internet or email, such as Amish producers. Extension specialists used other strategies to work around this challenge. For example, specialists used newspapers, guide sheets, handbooks, and research articles to provide information to producers without internet access. With the permission farmers, they also visited the farms alone and then discussed findings by phone. When specialists could not visit a farm, they invited farmers to send photos of problem areas via traditional mail and used the photos for telephone consultations.

\section{Partnerships with Other Organizations}

Extension specialists served as advisory members to many partner organizations as they collaborated to navigate the challenges introduced by the pandemic. Contacts established prior to the pandemic reached out to StrikeForce team members on multiple occasions to request support for their efforts. For example, the Oregon County Farmers Market reached out to Jamie Gundel, an Agronomy Field Specialist and StrikeForce project team member, to represent them and serve as a panelist for Innovative Ideas Emerging Among Farmers Markets in Missouri, a roundtable discussion held April 20th. This Zoom session was open to the public and included speakers from four small Missouri farmers markets. The goal of the discussion was to share ideas and protocols farmers markets were using to stay open amid the COVID-19 pandemic. On behalf of the Oregon County Farmers Market, Gundel explained how their market and vendors were adapting to continue selling locally grown produce. The Market had chosen not to open on their scheduled date of April 25, 2020 due to the risks to 
vendors and customers. They encouraged vendors to explore alternative methods to sell their products and encouraged customers to continue buying from local vendors. Vendors quickly pivoted to off-the-farm sales and home delivery of their goods. In contrast, the Nixa Farmers Market opened but was enforcing strict sanitation and social distancing guidelines as directed by the city. Other markets had not yet reached their opening dates but were planning to open while prioritizing sanitation and social distancing. After each farmers market manager or representative spoke, there was time assigned for questions and discussion, which led to sharing many good ideas. Much of the discussion shifted from COVID-19 adaptations to general management of the markets and their service to communities.

The Oregon County Farmers Market chose to open on their next scheduled date, May 30, 2020, and follow the guidelines from MUE regarding farmers markets (University of Missouri Extension, 2020a, 2020b). The market provided hand sanitizer at the entrance and exit points and asked all vendors to provide their own at their booths for use between transactions. All booth spaces were set a minimum of 10 feet apart to allow for greater social distancing of both vendors and customers. In addition, customers were asked to "shop with their eyes" and leave the market as soon as they were finished shopping, rather than standing and visiting with vendors or other customers.

\section{Conclusions}

When the pandemic reached Missouri in midMarch, the StrikeForce project team was in the right place at the right time. Extension specialists had developed trusting relationships with producers over the previous three years and were poised to assist producers through the pandemic as it altered their agricultural operations. Producers were willing to access online resources and educational materials that the StrikeForce project team created because the foundation of trust was already built.

Programs transitioned from in-person to online offerings starting in March. These programs included Apple Grafting, the Millsap Farms Twilight Tours, FSMA PSA produce safety training, and the Ag 101 series, offering five online sessions to help agriculture producers grow their business. StrikeForce online education and workshops reached nearly 600 participants, using a mix of Zoom video conferencing, pre-recorded videos, pictures, and teleconferencing. In addition, the team members provided mentoring to 66 farmers from March to the conclusion of the funding program in September 2020.

To a survey sent out by the StrikeForce project, farmers provided candid responses about how the pandemic affected their production and businesses. They experienced increased local demand, increased input costs, long waits for agricultural services such as processing, decreased on-farm customers, and a reduction or elimination of on-farm labor. Few took advantage of federally available financial support, partly due to the reporting of farmers market and direct-to-consumer sales not satisfying funding eligibility guidelines. The StrikeForce team responded to the COVID-19 pandemic by developing alternative strategies such as moving in-person workshops online and using pre-recorded videos, virtual instruction techniques, and livestreaming when face-to-face farm tours and individual farm consultations were made impossible by pandemic restrictions imposed by the state of Missouri. These alternative venues were still effective because the StrikeForce team had already developed relationships with community partners, farmer-to-farmer peers, mentor farmers, and smallscale, beginning specialty crop farmers. Mentor farmer Millsap stated:

There has never been a better time to get started in local food production, there is so much opportunity out there. With a little marketing we could have sold 100 more Community Supported Agriculture shares, we could be selling a lot more stuff at farmers markets if we had the produce, and there could be a lot more vegetable and fruit growers in the farmers markets. COVID-19 accelerated change in people's ability to jump in and have a market that is hungry, literally, and figuratively, for their (farmers) products. No one should be daunted now, in fact, they should be encouraged to take that leap. This presents a unique opportunity for people to 
get started as local food producers and may be the bridge needed for people to transition from earning a paycheck in the office to being a producer. (personal communication, September 24, 2020)

\section{Moving Forward}

When the StrikeForce project began three years ago, team members discussed a best-case scenario in which an online program would be developed to reach new audiences. At that time, MUE was not using videoconferencing and the project team did not have the necessary technological tools and training available, which was a barrier to completing the objectives of the project and to bringing the curricula online. While it was the intention of the project team to eventually develop the curricula and create on-demand access for growers, the pivot caused by the pandemic accelerated online program delivery and provided the technological tools and support for new modes of teaching on a reduced timeline. The information gathered from the innovative teaching methods piloted with specialty farmers during the pandemic will shape StrikeForce's programming going forward. However, persistent constraints, especially limited broadband access in rural Missouri, must be overcome to reach more producers. Looking forward, the StrikeForce project team plans to address the following goals:

- Ensure educational materials for workshops, including Ozark Ag 101, Apple Tree Grafting, and Food Safety, are available online and developed fully into online courses. The Ozark Ag 101 educators (Extension Regional Agricultural Specialists) are currently developing an online version of the course through Canvas, an online class platform, through the University of Missouri system. StrikeForce programming during the pandemic renewed interest in online coursework for specialty producers unable to attend in person.

- Expand use of videos and online livestreaming connections such as Zoom, YouTube, and Facebook to enhance individual farmer consultations. StrikeForce
COVID-19 efforts show that individual consultations can be both effective and efficient when videos and online connections are used to identify on-farm issues (Lake et al., 2020). It is especially helpful to farmers when specialists use video conferencing to collaborate across disciplines such as agronomy, horticulture, and agriculture business in order to meet diverse needs of producers. Video technology also enables the StrikeForce project to expand educational tools and resources more broadly across the state, reaching and building connections with farmers beyond the local driving radius.

- Continue to make educational materials available in the form of newsletters, guide sheets, and newspaper articles. The pandemic has highlighted that there is a sector of the population with little access to StrikeForce programming when face-toface classes are unavailable. This population includes the Mennonite and Amish communities as well as those who simply prefer not to engage with digital technologies despite having broadband available, such as some seniors. In addition, where broadband connectivity can be unreliable may limit the use of technology. In these situations, Extension specialists can accommodate requests by providing information in print through pick up, delivery, or mail. Further development is needed to ensure continued support of these communities.

- CDC guidelines and University restrictions for in-person meetings during COVID-19 limited options for classroom-style teaching. However, there are strategies for faceto-face instruction during the pandemic. Small classes of less than 10 people and strict adherence to social distancing, masking, personal hygiene habits, and enforcing local policy form a viable strategy for working with non-digital audiences.

- Build on existing programming and expand strategies to promote Missouri's varied agricultural landscape, addressing both shortterm challenges and long-term needs (White 
et al., 2020). Promoting the diversity of agricultural landscapes in Missouri is critical to the long-term economic impact of the StrikeForce Farmer Development project. Lessons learned in the project are transferable to all Cooperative Extension. For example, many programs would not have been possible without the financial resources made available through a grant to cover mileage expenses for County Extension offices, equipment needed for instruction (e.g., apple grafting supplies), and resources needed for online teaching (e.g., salary offset for instructor time, support costs for online programming fees and curricula fees).

- The development of a team of specialists with different areas of expertise, who work together towards a common goal, is an invaluable outcome of the StrikeForce project. More than the technology, it was the collaborative environment within the team that led to the innovation and outreach of the project. The StrikeForce team was prepared to deal with the effects of the pandemic on farmers because they had already built the foundation of working together to solve a challenge. Teamwork was central to the success of the project and should be prioritized when addressing future needs or challenges. By maintaining a focus on teamwork after the pandemic, specialists will remain prepared for any future challenge the project may face.

The innovations implemented by the StrikeForce team to advance activities during the pandemic resulted in novel programming approaches which will continue beyond the pandemic. As we capitalize on this momentum, specialists will continue to innovate and develop new strategies that increase the reach of the project. For others who face similar challenges and want to take this path, we recommend: (1) Establish a team of trusted individuals, (2) Know your target audience, and (3) "Don't be afraid to try it."

\section{Acknowledgments}

The StrikeForce Farmer Development team recognizes Dr. Rob Kallenbach, Associate Dean of University of Missouri Extension and Senior Program Director of Agriculture and Environment Extension, for initiating the project and for his ongoing support.

\section{References}

Byers, P. L., Patillo, A. R., Gundel, J. A., Denkler, S. R., Peregoy, K. B, Lake, A. K., ... \& Burton, D. L. (2020). StrikeForce farmer development final project report. Unpublished manuscript.

Federal Communications Commission [FCC]. (2016). 2015 Broadband progress report and notice of inquiry on immediate action to accelerate deployment (GN Docket No. 14-126). Washington, DC: FCC. https://docs.fcc.gov/public/attachments/FCC-15-10A1.txt

Lake, A. K., Byers, P. L., Patillo, A. R., Gundel, J. A., Peregoy, K. B, \& Meusch, E. N. (2020). StrikeForce farmer development COVID-19 PowerPoint. Unpublished manuscript.

Missouri Broadband Resource Rail. (2019). Broadband access, Percent population in a high-speed internet service area by county.

Columbia: University of Missouri, Missouri Broadband Resource Rail. Retrieved April 6, 2021, from

https://mobroadband.org/story-maps-map-

room/ ?action $=$ link map\&ids $=28908,24868,33002 \& v m=33002, \mathrm{r} 2, \mathrm{r} 8, \mathrm{r} 3 \& \mathrm{bbox}=-$ $11070291.53369239,4180769.7465714673,-$

9509753.164222647, 5074777.229394651\&opacity $=\% 7 \mathrm{~B} \% 2233002 \% 22: 0.7, \% 22 \mathrm{r} 2 \% 22: 1, \% 22 \mathrm{r} 8 \% 22: 0.4, \% 22 \mathrm{r} 3 \% 22$ : $0.8 \% 7 \mathrm{D}$

Ostrom, M., Cha, B., \& Flores, M. (2010). Creating access to land grant resources for multicultural and disadvantaged farmers. Journal of Agriculture, Food Systems, and Community Development, 1(1), 89-105.

https://doi.org/10.5304/jafscd.2010.011.011 
U.S. Department of Agriculture [USDA]. (2017, February). Small farms, big differences [Blog post]. Washington, DC: USDA. https://www.usda.gov/media/blog/2010/05/18/small-farms-bigdifferences\#: : :text=USDA $\% 20$ defines $\% 20 \mathrm{a} \% 20$ small $\% 20 \mathrm{farm}, \mathrm{cash} \% 20 \mathrm{farm} \% 20$ income $\% 20$ under $\% 20 \% 24250 \%$ 2C000.\&text $=$ While $\% 20$ most $\% 20$ U.S. $\% 20$ farms $\% 20$ are, market $\% 20$ value $\% 20$ of $\% 20$ agricultural $\% 20$ production

USDA. (2016a, January). StrikeForce initiative for rural growth and opportunity [Press Release]. Washington, DC: USDA. https://www.usda.gov/sites/default/files/documents/strikeforce-rural-growth-opportunity.pdf

USDA. (2016b, January 15). USDA's StrikeForce initiative invests $\$ 23.5$ billion in rural communities, expands to four new states [Press Release]. Washington, DC: USDA. https://www.usda.gov/media/press-releases/2016/01/15/usdasstrikeforce-initiative-invests-235-billion-rural-communities

USDA, Natural Resources Conservation Service Missouri. (n.d.). USDA StrikeForce funding boosts farm profits in low-income counties [Press Release]. Columbia: USDA NRCS Missouri. https://www.nrcs.usda.gov/wps/portal/nrcs/mo/newsroom/stories/NRCSEPRD1309091/

University of Missouri Center for Applied Research and Engagement Systems. (2019). Missouri broadband access: The state of broadband in Missouri. Columbia,: University of Missouri, CARES.

https://apps.cares.missouri.edu/portal/apps/MapSeries/index.html?appid=d4a2252250db472e985a6ead1a1d4ed7

University of Missouri Extension. (2020a, April). COVID-19 farmers markets: Steps for customers to shop safely [Guide sheet]. Columbia: University of Missouri Extension, Missouri Farmers Market Association. https://extension2.missouri.edu/media/wysiwyg/Extensiondata/ExtensionWay/Docs/covid-19/COVID-19FarmersMarketShoppers.pdf

University of Missouri Extension. (2020b, April). COVID-19: Fresh produce sales and marketing [Guide Sheet]. Columbia: University of Missouri Extension, Missouri Farmers Market Association. https://extension2.missouri.edu/media/wysiwyg/Extensiondata/ExtensionWay/Docs/covid-19/COVID-19AdaptingMarketingChallenges.pdf

University of Missouri Extension. (2021). Mission, vision, and values. Columbia: University of Missouri Extension. https://extension.missouri.edu/about-us/mission-vision-and-values

White, M. C., Rahe, M., Milhollin, R., Horner, J., Russell, R., Presberry, J., \& Kuhns, M. (2020). Workforce needs assessment of Missouri's food, agriculture and forestry industries. Truxton, MO: Missouri Department of Agriculture, Missouri Agricultural Foundation. https://extension.missouri.edu/media/wysiwyg/Extensiondata/Int/BusinessAndCommunity/Docs/WorkforceNe edsAssessment.pdf 